\title{
Further Mutational Studies on the PAS Resistance of Mycobacterium tuberculosis var. hominis
}

\author{
By M. TSUKAMURA \\ The Obuso National Sanatorium, Obu, Aichi-ken, Japan
}

(Received 10 September 1959)

\begin{abstract}
SUMMARY
Mutational studies on the PAS (sodium $p$-aminosalicylate) resistance of $M y c o$ bacterium tuberculosis var. hominis, strain $\mathrm{H} 37 \mathrm{RV}$ have been carried out. It has been assumed that one type of population structure of clones with relation to drug resistance corresponds to one genotype. Clones derived from single colonies obtained on different PAS concentrations produced three types of population structure; the first type is similar to the population structure of the parent strain which has not been previously exposed to the drug and its degree of resistance is up to $0 \cdot 2 \mu \mathrm{g}$. PAS $/ \mathrm{ml}$. The second and the third types are different from the parent strain and their degrees of resistance are up to 3 and $1000 \mu \mathrm{g}$. PAS $/ \mathrm{ml}$, , respectively. Neither intermediate population structures nor intermediate degrees of resistance were clearly observed. From these results, it may be concluded that there are only two genotypes responsible for PAS resistance, one determining a lower, and the other a higher degree of resistance.
\end{abstract}

\section{INTRODUCTION}

Szybalski \& Bryson (1953) reported from their studies of survival curves of Bacillus megaterium to PAS ( $p$-aminosalicylate) that resistance is a single step pattern. However, genetic information on the PAS resistance of micro-organisms is still scanty (Bryson \& Szybalski, 1955) and the purpose of this paper is to study the PAS resistance of Mycobacterium tuberculosis from the mutational aspect.

\section{METHODS}

Strain. Mycobacterium tuberculosis var. hominis, strain H37 Rv, was used throughout. The parent strain was derived from a single colony.

Medium. Ogawa's egg medium was prepared as follows : basal solution $\left(1 \% \mathrm{KH}_{2} \mathrm{PO}_{4}\right.$ and $1 \%$ sodium glutamate), $100 \mathrm{ml}$; whole eggs, $200 \mathrm{ml}$; glycerol, $6 \mathrm{ml}$; $2 \%$ aqueous solution of malachite green, $6 \mathrm{ml}$. The medium was poured in $8 \mathrm{ml}$. amounts into tubes, $170 \times 17$ to $18 \mathrm{~mm}$., sloped, and sterilized at $90^{\circ}$ for $60 \mathrm{~min}$. PAS sodium $p$-aminosalicylate (Shionogi Co.) was dissolved in distilled water and added to the medium before sterilization.

Population structure of the clone. As the characters of a single organism cannot be observed, those in relation to drug resistance may be expressed as the population structure of a clone. The present study was conducted by assuming that one type of population structure (character) of a clone represents one phenotype, and probably corresponds to one genotype. Colony size on a given drug 
concentration cannot be used in this instance as a measure of the character (the degree of resistance), since colony size is affected considerably by experimental conditions. There is, for example, a variation in colony size depending upon the number of colonies per unit area of medium, even among those colonies derived from cells belonging to the same clone and having the same genotype. Thus, in order to obtain data independent of such variation, the degree of resistance was expressed as the population structure of a clone, which was measured by its survival ratios on different concentrations of PAS.

Method of determining the survival ratio. A single colony was picked and subcultured on media without drug for 6 weeks. The resulting culture was suspended in saline after shaking with glass beads for $10 \mathrm{~min}$. Tenfold dilutions were made from this suspension, and $0.02 \mathrm{ml}$. of each dilution inoculated on to a set of media containing graded concentrations of PAS and to control media without PAS. The inoculation was made by a whirl loop delivering $0.02 \mathrm{ml}$. (Tsukamura \& Noda, 1957). Counts were made after 4 weeks of incubation, and the number of surviving colonies was determined as an average of ten replicates.

\section{RESULTS}

\section{Population structure of the parent strain not exposed to $P A S$}

The results on the population structure of the parent strain, expressed as survival ratios on various concentrations of PAS, are shown in Table 1 . It will be noted that the survival ratio dropped discontinuously at a concentration between $0 \cdot 1$ and $0 \cdot 2 \mu \mathrm{g}$. PAS $/ \mathrm{ml}$., and decreased slowly between $0 \cdot 2$ and $1 \mu \mathrm{g}$. PAS $/ \mathrm{ml}$. Survivors capable of growing on media containing more than $10 \mu \mathrm{g}$. PAS $/ \mathrm{ml}$. were not found among c. $10^{9}$ viable cells of the parent strain tested.

Table 1. Population structure of the parent strain not exposed to PAS. Test organism: Mycobacterium tuberculosis var. hominis, strain $H 37 R v$

\begin{tabular}{|c|c|c|c|c|c|}
\hline \multirow{2}{*}{$\begin{array}{c}\text { Concentration } \\
\text { of PAS }(\mu \mathrm{g} . / \mathrm{ml} .)\end{array}$} & \multicolumn{4}{|c|}{$\begin{array}{l}\text { Number of survivors } \\
\text { Dilution of cell suspension* }\end{array}$} & \multirow[b]{2}{*}{ Survival ratio } \\
\hline & $10^{-8}$ & $10^{-4}$ & $10^{-1}$ & 10 & \\
\hline $\mathbf{0}$ & $42 \cdot 9 \pm 6 \cdot 04$ & $\mathbf{M}$ & $\mathbf{M}$ & $\mathbf{M}$ & $1 \cdot 00$ \\
\hline 0.01 & $36 \cdot 0 \pm 8 \cdot 40$ & $\mathbf{M}$ & $\mathbf{M}$ & $\mathbf{M}$ & $0 \cdot 839$ \\
\hline 0.02 & $34 \cdot 5 \pm 6 \cdot 15$ & $\mathbf{M}$ & $\mathbf{M}$ & $\mathbf{M}$ & $0 \cdot 840$ \\
\hline 0.05 & $32 \cdot 2 \pm 5 \cdot 81$ & $\mathbf{M}$ & $\mathbf{M}$ & $\mathbf{M}$ & 0.750 \\
\hline $0 \cdot 1$ & $0 \cdot \overline{6}$ & un & $\bar{M}$ & $\mathbf{M}$ & $1.40 \times 10^{-2}$ \\
\hline $0 \cdot 2$ & $\mathbf{0}$ & un & $0.5 \mathrm{~m}$ & $\mathbf{M}$ & $1.16 \times 10^{-7} \dagger$ \\
\hline 0.3 & 0 & 0 & 0.9 & $\mathbf{m \ddagger}$ & $2.09 \times 10^{-7}$ \\
\hline 0.5 & $\mathbf{0}$ & $\mathbf{0}$ & $0 \cdot 3$ & $3 \cdot 3 \pm 1 \cdot 78$ & $7 \cdot 68 \times 10^{8}$ \\
\hline 0.7 & $\mathbf{0}$ & $\mathbf{0}$ & 0 & $1 \cdot 8 \pm 0.47$ & $4.19 \times 10^{-8}$ \\
\hline 1 & $\mathbf{0}$ & 0 & $\mathbf{0}$ & $\mathbf{0} \cdot \mathbf{3}$ & $6.99 \times 10^{-9}$ \\
\hline
\end{tabular}

* Number of survivors obtained by inoculating samples of cell suspensions to media containing different concentrations of PAS. (Mean of ten replicates) \pm (standard deviation).

+ Not accurate because of the membraneous growth appearing as a background.

‡Distinguishable large colonies were not observed in these media. The phenomenon could be explained as an interference phenomenon of the growth of resistant colonies with that of many sensitive colonies which have appeared as a thin membraneous growth resulting from the retarded growth rate caused by PAS (Tsukamura et al. $1959 \mathrm{~b}$ ).

un, uncountable; $m$, thin membraneous growth; $M$, membraneous growth. 


\section{Population structures of clones derived from single colonies grown on media containing 0.3-1 $\mu \mathrm{g} . P A S / m l$.}

Clones were obtained by the first-step selection from the parent strain with $0 \cdot 1-$ $1 \mu \mathrm{g}$. PAS $/ \mathrm{ml}$. Two to five single colonies were picked from media containing $0 \cdot 1$, $0.3,0.5,0.7$, and $1 \mu \mathrm{g} . / \mathrm{ml}$., and were subcultured on media without drug to form large populations. The resulting clones were designated P0.1R, P0.3R, P0.5R, P0.7R, and P1R, respectively. Population structures of these clones were analysed and some characteristic results are shown in Table 2.

Table 2. Population structures of clones derived from single colonies selected from media containing different concentrations of $P A S$, which were inoculated with the parent strain

\begin{tabular}{|c|c|c|c|c|c|}
\hline \multirow{2}{*}{$\begin{array}{c}\text { PAS } \\
(\mu \mathrm{g} \cdot / \mathrm{ml} .)\end{array}$} & \multicolumn{5}{|c|}{ Numbers of survivors from clones* } \\
\hline & Po.1 R & P0.3R & P0.5R & P0.7R & P1R \\
\hline $\mathbf{0}$ & $55 \cdot 5 \pm 10 \cdot 4$ & $137 \cdot 6 \pm 33 \cdot 2$ & $40 \cdot 5 \pm 3 \cdot 54$ & $32 \cdot 8 \pm 6 \cdot 34$ & $78 \cdot 1 \pm 21 \cdot 8$ \\
\hline $0 \cdot 3$ & $\mathbf{0}$ & $115 \cdot 8 \pm 12 \cdot 1$ & $34 \cdot 3 \pm 7 \cdot 73$ & $31 \cdot 5 \pm 4 \cdot 54$ & $50 \cdot 2 \pm 15 \cdot 9$ \\
\hline 0.5 & $\mathbf{0}$ & $110 \cdot 0 \pm 21 \cdot 0$ & $26 \cdot 9 \pm 5 \cdot 69$ & $30 \cdot 8 \pm 5 \cdot 70$ & $42 \cdot 2 \pm 7 \cdot 42$ \\
\hline $0 \cdot 7$ & $\mathbf{0}$ & $121 \cdot 7 \pm 24 \cdot 8$ & $30 \cdot 0 \pm 4.98$ & $34 \cdot 6 \pm 2 \cdot 79$ & $42 \cdot 3 \pm 12 \cdot 9$ \\
\hline 1 & $\mathbf{0}$ & $104 \cdot 7 \pm 27 \cdot 8$ & $20 \cdot 4 \pm 7 \cdot 32$ & $35 \cdot 6 \pm 4 \cdot 91$ & $44 \cdot 8 \pm 8 \cdot 33$ \\
\hline 2 & 0 & $45 \cdot 2 \pm 21 \cdot 1$ & $12 \cdot 8 \pm 4 \cdot 16$ & $24 \cdot 8 \pm 4 \cdot 59$ & $61 \cdot 3 \pm 14 \cdot 2$ \\
\hline $\mathbf{3}$ & $\mathbf{0}$ & $2 \cdot 2 \uparrow$ & $8 \cdot 4 \pm 2 \cdot 16 \dagger$ & $14.0 \pm 3.94 \dagger$ & $11 \cdot 7 \pm 9.41 \dagger$ \\
\hline 5 & $\mathbf{0}$ & 0 & $\overline{0}$ & $\overline{0}$ & $\overline{0}$ \\
\hline 10 & $\mathbf{0}$ & $\mathbf{0}$ & $\mathbf{0}$ & $\mathbf{0}$ & 0 \\
\hline
\end{tabular}

* (Mean of ten replicates) \pm (standard deviation). Clones designated P0.1R, P0.3R, P0.5R P0.7R, P1 R were picked from media containing $0 \cdot 1,0 \cdot 3,0 \cdot 5,0 \cdot 7$, and $1 \cdot 0 \mu \mathrm{g} . / \mathrm{ml}$. PAS, respectively, after inoculating with parental strain. $†$ Small colonies.

All the clones tested, excepting P0.1 R and some of P0.3R (not shown in Table 2) showed similar population structures, although they had been obtained on media containing different concentrations of PAS. The degree of resistance of the clones was about 2 or $3 \mu \mathrm{g}$. PAS $/ \mathrm{ml}$. As mentioned previously, this suggests that these clones had the same genotype. The mutation frequency (appearance rate of resistant mutants among total viable population) to this phenotype from the wild phenotype appears to be about $10^{-7}$ to $10^{-8}$ (see Table 1 ).

The clone $\mathbf{P 0} \cdot 1 \mathrm{R}$ represented a population structure distinctly different from that of the other clones, resembling that of the parent strain. This clone appears to have the wild phenotype, although an intermediate phenotype between that of the parental strain and of the clones P0.3R to P1R has not been excluded.

Two types of colonies grew on media containing $0 \cdot 3 \mu \mathrm{g} . \mathrm{PAS} / \mathrm{ml}$. by the first-step selection: some large colonies and some small colonies. Two clones derived from large colonies and three clones derived from small colonies were tested for their population structures. The former showed a degree of PAS resistance of 2-3 $\mu \mathrm{g}$. PAS $/ \mathrm{ml}$. and were considered to have the resistant genotype different from the wild genotype. On the other hand, the latter showed a degree of resistance up to $0.3 \mu \mathrm{g}$. PAS $/ \mathrm{ml}$. only. These clones were again subcultured on drug-free media and analysed for their population structures. On this occasion these clones showed a degree of resistance up to $0 \cdot 1 \mu \mathrm{g}$. PAS $/ \mathrm{ml}$. It therefore appeared that the properties of the 
original small clones surviving on media containing up to $0 \cdot 3 \mu \mathrm{g}$. PAS $/ \mathrm{ml}$. were only fluctuative and may not be due to a change of genotype.

Survivors capable of growing on media containing 10 and $100 \mu \mathrm{g}$. PAS $/ \mathrm{ml}$. were found in the clones P1R at rates of about $10^{-6}$. An example of these experiments is shown in Table 3. Two additional experiments made independently showed that the appearance of survivors growing on media containing $10 \mu \mathrm{g}$. PAS $/ \mathrm{ml}$. among the total viable population were $1.78 \times 10^{-6}$ and $5.41 \times 10^{-6}$ and those of survivors growing on media containing $100 \mu \mathrm{g}$. PAS/ml. were $5 \cdot 22 \times 10^{-7}$ and $1 \cdot 29 \times 10^{-6}$.

Table 3. Rate of appearance of mutants resistant to 10 and $100 \mu \mathrm{g}$. PAS/ml. in the clone $P 1 R$ obtained by the first-step selection of the parent strain with $1 \mu g . P A S / m l$.

\begin{tabular}{|c|c|c|c|}
\hline \multirow{2}{*}{$\underset{(\mu \mathrm{g} \cdot / \mathrm{ml} .)}{\text { PAS }}$} & \multicolumn{2}{|c|}{$\begin{array}{l}\text { Number of survivors at a } \\
\text { dilution of cell suspension }\end{array}$} & \multirow[b]{2}{*}{ Survival ratio } \\
\hline & $10^{-6}$ & 10 & \\
\hline $\mathbf{0}$ & $47 \cdot 8 \pm 18 \cdot 7$ & Membraneous & 1.00 \\
\hline 1 & $48 \cdot 7 \pm 18 \cdot 2$ & Membraneous & 1.02 \\
\hline 10 & 0 & $10 \cdot 0 \pm \theta \cdot 01$ & $2.09 \times 10^{-6}$ \\
\hline 100 & $\mathbf{0}$ & $3 \cdot 4 \pm 2 \cdot 41$ & $7 \cdot 10 \times 10^{-7}$ \\
\hline 1000 & 0 & $2 \cdot 7 \pm 1.79$ & $5.65 \times 10^{-7}$ \\
\hline 2000 & $\mathbf{0}$ & 0 & $<2.09 \times 10^{-8}$ \\
\hline
\end{tabular}

Table 4. Population structures of clones, $P 10 R$ and $P 100 R$, derived from single colonies of the clone $P 1 R$ (see Table 3) grown on media containing 10 and $100 \mu \mathrm{g}$. $\boldsymbol{P A S} / \mathrm{ml}$.

PAS $(\mu \mathrm{g} . / \mathrm{ml}$.
0
1
10
100
500
1000
2000

Number of survivors (survival ratio)

\begin{tabular}{cc}
\hline P10R & P100R \\
$81 \cdot 5 \pm 15 \cdot 7(1 \cdot 00)$ & $19 \cdot 4 \pm 8 \cdot 75(1 \cdot 00)$ \\
$63 \cdot 0 \pm 4 \cdot 79(0 \cdot 77)$ & $15 \cdot 5 \pm 4 \cdot 36(0 \cdot 80)$ \\
$15 \cdot 5 \pm 5 \cdot 16(0 \cdot 19)$ & $6 \cdot 6 \pm 2 \cdot 49(0 \cdot 34)$ \\
$10 \cdot 0 \pm 1.76(0 \cdot 12)$ & $4 \cdot 7 \pm 2 \cdot 56(0 \cdot 24)$ \\
$13 \cdot 8 \pm 5 \cdot 45(0 \cdot 17)$ & $5 \cdot 0 \pm 2 \cdot 49(0 \cdot 26)$ \\
$1 \cdot 7 \pm 0.49(0 \cdot 02)$ & $2 \cdot 9 \pm 2 \cdot 29(0 \cdot 15)$ \\
0 & 0
\end{tabular}

* (Mean of ten replicates) \pm (standard deviation).

Population structures of clones derived from single colonies grown on media containing 10 and $100 \mu \mathrm{g}$. PAS $/ \mathrm{ml}$.

Single colonies were picked from media containing either 10 or $100 \mu \mathrm{g}$. PAS $/ \mathrm{ml}$, after inoculation from the clone $P 1 R$, and subcultured on drug-free media. The resultant clones were named $\mathrm{P} 10 \mathrm{R}$ and $\mathrm{P} 100 \mathrm{R}$, respectively. These clones represented a population structure different from that of the original P1R, from which they were derived, but they were similar to each other. The results shown in Table 4 indicate that these clones, P10R and P100R, have a new phenotype producing a degree of resistance up to $1000 \mu \mathrm{g}$. PAS $/ \mathrm{ml}$. Two additional experiments made independently also gave similar results. 
Population structure of a clone derived from a single colony grown on media
containing $1000 \mu \mathrm{g} . P A S / m l$.

A single colony was picked from the surviving colonies of the clone P100R which had grown on media containing $1000 \mu \mathrm{g}$. PAS $/ \mathrm{ml}$. and subcultured on drug-free media to form a large population. The resulting clone, P1000R, was analysed for its population structure, which was found to be similar to clone P100R from which it was derived (Table 5). This means that clones P100R and P1000R have the same phenotype.

Table 5. Population structure of clone, P1000R, derived from a single colony of the clone P $100 R$ (see Table 4) grown on media containing $1000 \mu \mathrm{g} . P A S / m l$.

\begin{tabular}{|c|c|c|c|}
\hline \multirow[b]{2}{*}{ PAS $(\mu \mathrm{g} . / \mathrm{ml})}$. & \multicolumn{2}{|c|}{$\begin{array}{l}\text { Number of survivors at } \\
\text { dilution of cell suspension* }\end{array}$} & \multirow[b]{2}{*}{ Survival ratio } \\
\hline & $10^{-3}$ & 10 & \\
\hline $\mathbf{0}$ & $108 \cdot 9 \pm 12 \cdot 7$ & & $(1 \cdot 00$ \\
\hline 1 & $91 \cdot 6 \pm 15 \cdot 6$ & & $0 \cdot 840$ \\
\hline 10 & $86 \cdot 8 \pm 19 \cdot 2$ & Uncountable & 0.796 \\
\hline 100 & $60 \cdot 0 \pm 10 \cdot 3\}$ & & 0.550 \\
\hline 500 & $56 \cdot 8 \pm 13.2$ & & 0.522 \\
\hline 1000 & $16 \cdot 6 \pm 10 \cdot 0$ & & $0 \cdot 152$ \\
\hline 2000 & $\overline{0}$ & $2 \cdot 4 \pm 1.95$ & $2 \cdot 20 \times 10^{-5}$ \\
\hline 3000 & 0 & $\overline{0}$ & $<\theta .18 \times 10^{-8}$ \\
\hline
\end{tabular}

Table 6. Population structure of a clone, P2000R, derived from a single colony of the clone P1000R (see Table 5) grown on media containing $200 \mu \mathrm{g} . P A S / m l$.

$\begin{array}{ccc}\text { PAS }(\mu \mathrm{g} . / \mathrm{ml} .) & \text { Number of survivors* } & \text { Survival ratio } \\ 0 & 46 \cdot 1 \pm 10 \cdot 1 & 1 \cdot 000 \\ 1 & 50 \cdot 3 \pm 9 \cdot 60 & 1 \cdot 09 \\ 10 & 43 \cdot 3 \pm 8 \cdot 62 & 0 \cdot 940 \\ 100 & 43 \cdot 5 \pm 9 \cdot 95 & 0.945 \\ 500 & 41 \cdot 1 \pm 8 \cdot 83 & 0 \cdot 892 \\ 1000 & 3 \cdot 1 \pm 2 \cdot 56 & 6.74 \times 10^{-8} \\ 2000 & 0 & <2 \cdot 17 \times 10^{-3}\end{array}$

* (Mean of ten replicates) \pm (standard deviation).

A few cells of the clone P1000R survived on media containing $2000 \mu \mathrm{g}$. PAS $/ \mathrm{ml}$. to produce colonies at a rate of about $10^{-5}$ (Table 5). In order to test whether these colonies surviving on media containing $2000 \mu \mathrm{g}$. PAS $/ \mathrm{ml}$. have a different phenotype from the mother clone, P1000R, the population structure of the clone P2000R derived from a single colony grown on media containing $2000 \mu \mathrm{g}$. PAS $/ \mathrm{ml}$. was analysed. If this clone had the same phenotype as the clone $\mathrm{P} 1000 \mathrm{R}$, that is, if it had survived on media containing $2000 \mu \mathrm{g}$. PAS $/ \mathrm{ml}$. by phenotypic variability, it should produce a population structure similar to that of the mother clone P1000R. However, if its phenotype were different to that of the mother clone, that is, if it had survived on such media by mutation, it should produce a different population structure from that of the mother clone. The results indicated that the population structure of the clone P2000R was similar to that of the clones P10R, P100R 
and P1000R (Table 6). This means that the clone P2000R has the same phenotype as the clones P10R, P100R and P1000R, in spite of the fact that the cell, from which the clone $\mathrm{P} 2000 \mathrm{R}$ was derived, had once grown on media containing $2000 \mu \mathrm{g}$. PAS/ml., and that its survival on media containing $2000 \mu \mathrm{g}$. PAS $/ \mathrm{ml}$. was produced by phenotypic variability.

Survivors on media containing $3000 \mu \mathrm{g}$. PAS $/ \mathrm{ml}$. were not found among about $10^{5}$ viable cells of the clone $\mathrm{P} 1000 \mathrm{R}$ (Table 5). It therefore appears that the limit of PAS resistance in the test organism may be $2000 \mu \mathrm{g} . / \mathrm{ml}$.

\section{DISCUSSION}

From the results obtained, it is suggested that three types of population structures exist showing three levels of clonal PAS resistance. The first is the population structure of the parent strain, the clone P0.1R, and some of the clones P0.3R, with a degree of resistance up to $0.2 \mathrm{PAS} / \mathrm{ml}$. The second is the population structure of the clones P0.3R, P0.5R, P0.7R and P1R, with a degree of PAS resistance up to $3 \mu \mathrm{g}$. PAS $/ \mathrm{ml}$. The third is the population structure of the clones P10R, P100R, $\mathrm{P} 1000 \mathrm{R}$ and P2000 PR, with a degree of PAS resistance up to $2000 \mu \mathrm{g}$. PAS $/ \mathrm{ml}$. It is evident that the second and the third types are produced by mutation, since survivors capable of producing these population structures appear discontinuously, and the property of PAS resistance is stably heritable. The second and the third population structures and degrees of resistance are thus considered to be produced by different genotypes from the wild genotype.

It is remarkable that clones derived from surviving colonies grown on different concentrations of PAS ranging from $0 \cdot 3$ to $2000 \mu \mathrm{g} . / \mathrm{ml}$. represented only two types of the population structures. This fact suggests that there are only two genotypes responsible for PAS resistance in the test organism.

Unlike the strains Aoyama-B Mycobacterium tuberculosis (Tsukamura, Noda, Yamamoto \& Hayashi, $1959 a, b)$, the genotype for higher resistance has not been found in the parent strain and has been found only in cells having the genotype for lower resistance in the test strain. The genotype for higher resistance may be produced by two mutations, the mutation of a gene responsible for lower resistance and the mutation of another gene that may act as a conditional factor.

\section{REFERENCES}

Bryson, V. \& Szybalski, W. (1955). Microbial drug resistance. Advanc. Genet. 7, 1.

SzYBalski, W. \& Bryson, V. (1953). One step resistance development to isoniazid and sodium-p-aminosalicylate. J. Bact. 66, 468.

Tsukamura, M. \& Noda, Y. (1957). The enumeration of viable tubercle bacilli by egg medium slants and whirl loop inoculation. Kekkaku 32, 639 (in Japanese).

Tsukamura, M., Noda, Y., Yamamoto, M. \& Hayashi, M. (1959a). Genetic considerations of the mechanism involved in PAS-resistant tubercle bacilli. Amer. Rev. Tuberc. 79, 371.

Tuskamura, M., Noda Y., Yamamoto, M. \& Hayashi, M. (1955 b). A genetic study on the PAS-resistance-system of Mycobacterium tuberculosis. Jap. J. Genet. 34, 43. 